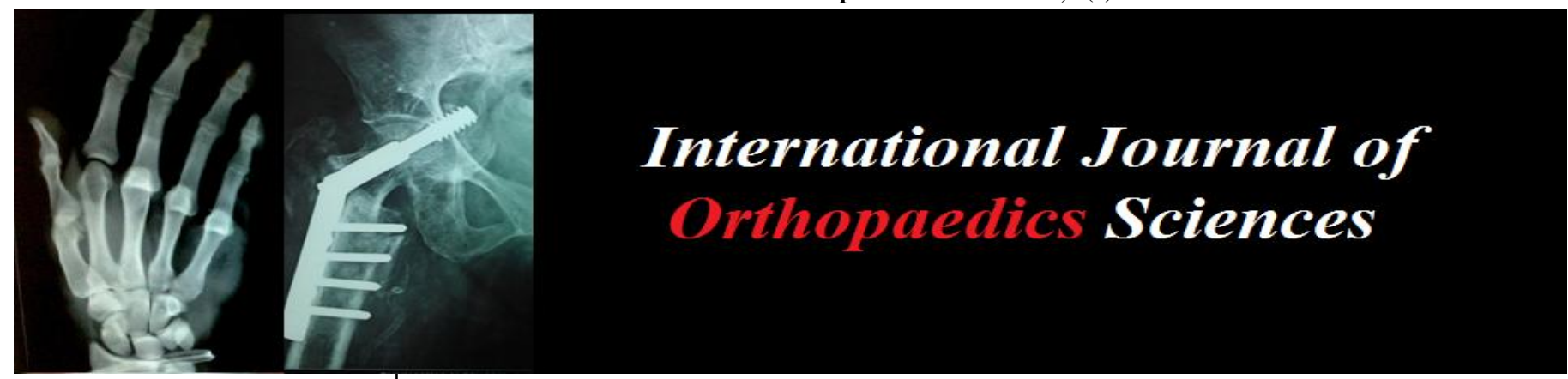

ISSN: $2395-1958$

IJOS 2018; 4(1): 750-752

(C) 2018 IJOS

www.orthopaper.com

Received: 29-11-2017

Accepted: 30-12-2017

Dr. D. Vimal Raj

Associate Professor, Department of Orthopaedics, Indira Gandhi

Medical College \& Research

Institute, Pondicherry, India

Dr. Anish Anto Xavier

Junior Resident, Department of

Orthopaedics, Indira Gandhi

Medical College \& Research

Institute, Pondicherry, India
Correspondence

Dr. D. Vimal Raj

Associate Professor, Department

of Orthopaedics, Indira Gandhi

Medical College \& Research

Institute, Pondicherry, India

\section{Functional and radiological outcome of intramedullary interlocking nail in the treatment of fracture shaft of humerus}

\author{
Dr. D. Vimal Raj and Dr. Anish Anto Xavier
}

DOI: https://doi.org/10.22271/ortho.2018.v4.i1k.109

Abstract

Fracture shaft of Humerus are one of the most common injuries of the arm caused by high velocity injury. Both direct and indirect forces act on it resulting in different fracture patterns. Based on the pattern humeral shaft fractures have been treated both by operative and nonoperative methods. Closed intramedullary nailing of these fractures has been the modality of choice for both segmental and communited fractures compared to plate and screw fixation. By this closed nailing procedure fracture complication, operative and post operative complications are reduced with good functional outcome and early restoration of pre morbid functions. The main purpose of the study was to evaluate the functional outcome and the role of locked intramedullary nailing in fracture shaft of humerus with respect to bone union, shoulder function and related complications. A study population was selected and was carried out with a total of 25 patients (male: 20, female: 5) treated with with intramedullary interlocking nail. The inclusion criteria were patients with closed humerus fracture less than 2 weeks and age more than 20 years. The selected patients were assessed both clinically and radiologically at regular intervals of $6 \mathrm{wks}$, 12 wks, 24 wks and 6 months thereafter till union. The functional outcome was accessed using Constant murley's scoring system. From our selected study sample we found majority of the patients had segmental fractures $(70 \%)$ and others had communited fractures $(30 \%)$. Based on the union, $80 \%$ of patients showed full union by 12 weeks and $20 \%$ showed full union by 16 to 20 weeks. We had 20 patients with excellent functional outcome at final follow-up while 5 patients had good outcome. Intramedullary interlocking nail is a quite safe, effective procedure associated with fast healing, good shoulder movements and reduced infection rates in humeral shaft fractures. Being a closed intramedullary procedure early mobilization and rehabilitation is possible with early restoration of premorbid functions.

Keywords: Intramedullary nail, rotational stability, shoulder function

\section{Introduction}

Fracture shaft of humerus is most common fracture encountered in general population sustaining injury due to simple or trivial fall, road traffic accidents, fall from heights, gunshot wounds resulting various fracture patterns such as spiral or to complex patterns such as communited or segmental. It can be treated by both operative and conservative. The main drawback of conservative method is prolonged period of immobilisation, which may result in stiffness of both shoulder and elbow joints. Humerus shaft fracture in adults are usually treated with either intramedullary interlocking nail or dynamic compression plate osteosynthesis or external fixator. Interlocking nail is more beneficial than plate osteosynthesis. They are less exposure, thereby preservation of soft tissues and preservation of fracture haematoma, provides good rotational stability.

\section{Materials and methods}

The study was conducted with a sample size of 25 patients with fracture shaft of humerus admitted in Pondy Surgical Centre, Puducherry from 2014-2016.The inclusion criteria such as patients with fractures of less than 3 weeks, Closed fractures and age above 20 including both sex groups and the exclusion criteria such as Fractures of more than 3 weeks, Open fractures, Age below 25 years were involved. 
The fractures were classified according to AO classification. The initial stabilisation was done by U-slab application. After clinical assessment, blood investigation and radiological work up was done and pre Anaesthetic check up obtained. All the patients underwent the proposed intramedullary interlocking nailing procedure. Type of surgery and the application of technique used for fixation of the implant was documented. Post operative care such as use of medications, regular wound inspection, suture removal and minimal mobilization. Patients were advised for regular follow ups on OPD basis at 4, 8, 12, 16,20 weeks post operatively. All the patients were assessed both clinically and radiologically. The outcome was accessed using Constant murley's scoring system.

\section{Operative Technique}

Patient put in the supine position. A longitudinal incision over the antero-lateral edge of the acromion of $2-3 \mathrm{~cm}$ is made obliquely forward near the tip of greater tuberosity. Deltoid fibres were split to reveal subacromial bursa and the rotator cuff. Rotator cuff is incised and an awl was passed medial to the tip of the greater tuberosity, $0.5 \mathrm{~cm}$ posterior to bicepital groove to make an entry point. The awl should be aimed at the medial cortex of humerus. Reduction is confirmed in Carm and a guide wire is passed and appropriate nail size is measured. Then guide wire is removed and the nail is passed till its proximal end. Proximal locking was done first and distal locking was done using free hand technique. Fracture reduction and position of the implant were assessed with $\mathrm{C}$ Arm.

\section{Results and discussion \\ Results}

The study was conducted on all the 25 patients with our proposed surgery and they were assessed radiologically and clinically for signs of fracture healing during each visit at 4,8 , $12,16,20$ weeks. Shoulder function is assessed using Constant murley scoring system. Most of the patients had excellent rates of fracture union and functional outcome with no pain and were able to do almost all their routine activities without any difficulty and few patients had good rates of fracture union with mild pain during terminal range of motion, with a mild difficulty in performing their daily activities. In our study the average time for union is 12 weeks. From our selected study sample we found majority of the patients had segmental fractures $(70 \%)$ and others had communited fractures $(30 \%)$. Based on the union, $80 \%$ of patients showed full union by 12 weeks and $20 \%$ showed full union by 16 to 20 weeks. We had 20 patients with excellent functional outcome at final follow-up while 5 patients had good outcome. There were no non-union cases in our study. The normal shoulder was used as the control group throughout the study for all the patients.

\section{Discussion}

Fracture shaft of humerus is a common fracture encountered in general population due to high energy trauma such as road traffic accidents, fall from height with outstretched hand or a direct blow to the arm. Humerus is a long bone which forms the shoulder joint proximally and connects the upper limb to the trunk. In cross section humerus is roughly cylindrical in shape proximally and slowly tapers down to triangular shape distally. Humerus has muscle attachments in the proximal, middle and distal aspects respectively. Angulation at the fracture site occurs due to the pull of the muscles acting on the proximal and distal fragments. In fractures of the proximal one third, between the insertion of pectoralis and deltoid, the proximal fragment is adducted due to the pull of pectoralis and deltoid pulls the distal fragment upward and laterally. In fractures occurring distal to both these insertions, the proximal fragment is abducted due to deltoid. The biceps brachii, coracobrachialis and triceps pulls the distal fragment proximally.

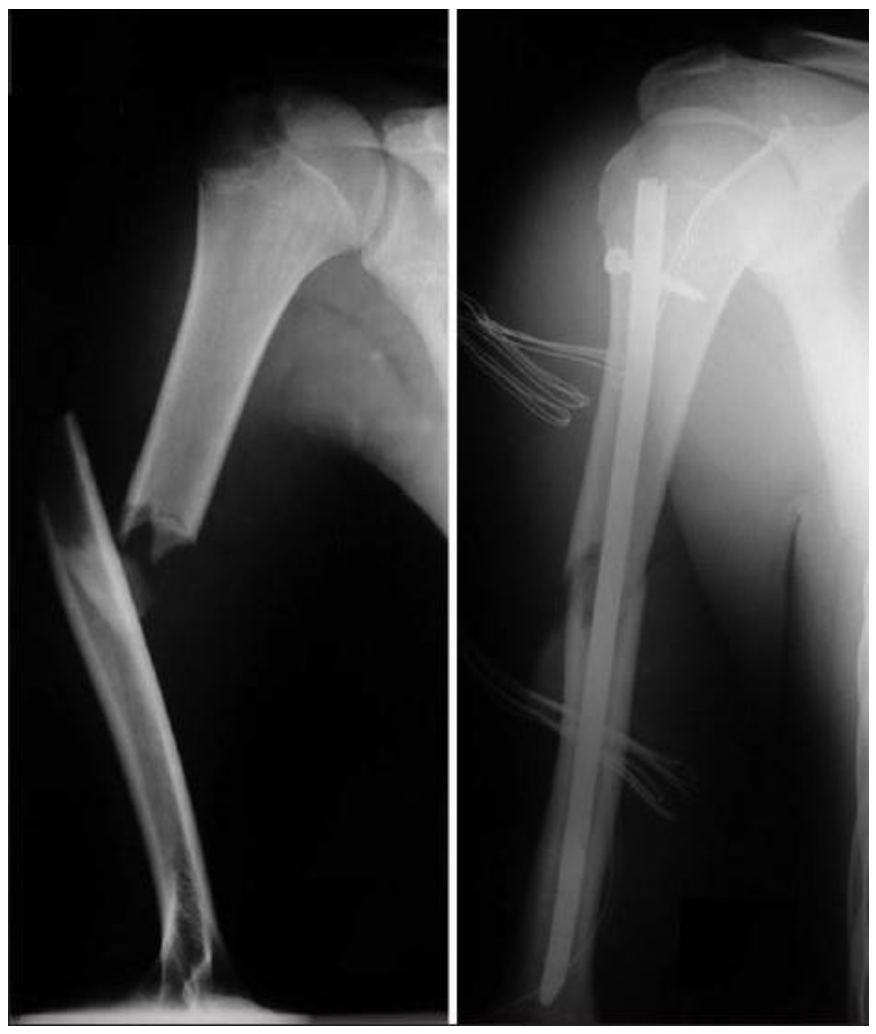

Management of fracture shaft of humerus is usually managed by conservative methods with success rate of more than $90 \%$. The use of plate osteosynthesis or intramedullary interlocking nail in the treatment of humerus shaft fracture has always been controversial. Plate osteosynthesis is always considered as the treatment of choice for fracture shaft of humerus. It provides compression at the fracture site and promotes osteosynthesis. But it is not suitable for pathological fractures, segmental fractures, comminuted fractures, nonunion and fractures proximal or distal to the shaft. Though plate osteosynthesis is considered as the treatment of choice, the results of intramedullary interlocking nail is comparable to that of plate osteosynthesis. Intramedullary nails are biomechanically superior as they are load sharing implants and they do not damage periosteal blood supply of the bone. They also have the advantage of less exposure thereby preserving soft tissues, less chance of infection and preservation of fracture hematoma thereby quicker fracture healing.

One of the most common complication occuring in fracture shaft of humerus is radial nerve palsy. Usually in a closed fracture, palsy occurs due to neuropraxia and nerve function spontaneously recovers within a period ranging from few weeks to several months. It is important to note that exploration for radial nerve integration should be carried out in all open fractures and a delayed exploration should be done in open fractures if no nerve recovery was found after 5-8 weeks. Antegrade nailing was carried for all the cases in our study. One of the common problems encountered with antegrade nailing is pain and shoulder dysfunction of varying degrees. But study has shown that if antegrade nailing is 
performed properly with minimal injury to rotator cuff, there is almost no shoulder dysfunction. nadequate repair of rotator cuff muscles, protruding nail head, injury to axillary nerve and comminution of humeral head intraoperatively are the important causes for shoulder dysfunction. Many authors suggested retrograde nailing as a better option than antegrade, but increased chance of iatrogenic fracture to the capitulum during entry and comes at a cost of elbow stiffness.

Studies have shown that post operatively, non-union rates ranges from 2 to $10 \%$, infection rates ranges from 2 to $4 \%$ and iatrogenic radial nerve palsy ranges from 2 to $7 \%$. In our study average time for fracture union was 12 weeks. There were no cases of non-union and infection in our study. There was no iatrogenic radial nerve palsy in our study.

In our study we have used constant murley's scoring system. From the shoulder assessment score in our study, outcome is good if the proximal portion of the nail is in a proper sinked position, no distraction at the fracture site and adequate stable fixation.

\section{Conclusion}

From our results we have encountered that intrameduallary interlocking nail is a good, effective and safe method of fixation for fracture shaft of humerus. Interlocking nail has considerable advantage over plate osteosynthesis. They are less exposure, thereby preservation of soft tissues and preservation of fracture haematoma, provides good rotational stability. Biomechanically intramedullary nails are better implants. They are subject to smaller bending load and have a less chance of fail due to fatigue. Less rate of infection and early mobilisation after surgery are the main advantages of this method of fixation with good anatomical reduction and stable fixation.

\section{References}

1. Gustilo RB, Anderson JT. Prevention of infection in the treatment of one thousand and twenty-five open fractures of long bones: retrospective and prospective analyses. J Bone Joint Surg Am. 1976; 58:453-58.

2. Chapman JR, Bradford HM. Randomized prospective study of humeral shaft fracture fixation: intramedullary nails versus plates. J Orthop Trauma. 2000; 14:162-6.

3. Sanzana ES, Dümmer RE, Castro JP et al. Intramedullary nailing of humeral shaft fractures. Int Orthop. 2002; 26:211-3.

4. McCormack RG, Brien D, Buckley RE, McKee MD, Powell J, Schemitsch EH. Fixation of fractures of the shaft of the humerus by dynamic compression plate or intramedullary nail. A prospective, randomized trial. J Bone Joint Surg. 2000; 82-B: 336-39.

5. Flinkkila $T$, Hyvonen $P$, Siira $P$, Hamalainen $M$. Recovery of shoulder joint function after humeral shaft fracture: a comparative study between ante grade intramedullary nailing and plate fixation. Arch Orthop Trauma Surg. 2004; 124:537-41. Epub 2004 Aug 24

6. Dalton JE, Salkeld SL, Satterwhite YE, Cook SD. A biomechanical comparison of intramedullary nailing systems for the humerus. J Orthop Trauma. 1993; 7(4):36774.

7. Browner BD, Levine AM, Jupiter JB, Trafton PG. Skeletal trauma. Philadelphia: Saunders, 1998.

8. Rommens PM, Blum J, Runkel M. Retrograde nailing of humeral shaft fractures. Clin Orthop. 1998; 350:26-39.

9. Browner BD, Levine AM, Jupiter JB, Trafton PG. Skeletal trauma. Philadelphia: Saunders, 1998.
10. Epps $\mathrm{CH} \mathrm{Jr}$, Grant RE. Fractures of the shaft of the humerus. In: Rockwood CA Jr, Green.

11. Bucholz DP, editors RW. Rockwood and Green's fractures in adults. 3rd ed. Philadelphia: Lippincott Williams \& Williams, 1991.

12. Sarmiento A, Waddell JP, Latta LL. Diaphyseal humeral fractures: treatment options. Instr Course Lect. 2002; 51:257-69.

13. Guse TR, Ostrum RF. The surgical anatomy of the radial nerve around the humerus. Clin Orthop Relat Res. 1992; 320:149-53.

14. Sarmiento A, Zagorski JB, Zych GA, Latta LL, Capps CA. Functional bracing for the treatment of fractures of the humeral diaphysis. J Bone Joint Surg. 2000; 82A:478-86.

15. Demirel M, Turhan E, Dereboy F, Ozturk A. Interlocking nailing of humeral shaft fractures: a retrospective study of 114 patients. Indian J Med Sci. 2005; 59:436-42.

16. Sarmiento A, Jagorski JB, Zych GA. Functional bracing for the treatment of the fractures of humeral diaphysis. $J$ Bone Joint Surg. 2000; 82:478-86.

17. Hoppenfeld S, deBoer $\mathrm{P}$. Surgical exposures in orthopaedics: the anatomic approach. Philadelphia: Lippincott Williams and Wilkins, 2003.

18. DeFranco MJ, Lawton JN. Radial nerve injuries associated with humeral fractures. J Hand Surg Am 2006; 31(4):655-63.

19. Shivarathre DG, Dheerendra SK, Bari A, Muddu BN. Management of clinical radial nerve palsy with closed fracture shaft of humerus - a postal questionnaire survey. Surgeon, 2008; 6(2):76-8.

20. YuLin Li, GuanhZhi N, Qiang Wu, Qiuli Wu, ShiQing F. Review of literature of radial nerve injuries associated with humeral fractures-An integrated management strategy, 2013; 8:I-11.

21. Strong GT. The epidemiology of humeral shaft fractures. J Bone Joint Surg. 1998; 80:249-53.

22. Gosler MW, Testroote M, Morrenhof JW, Janzing HM. Surgical versus non-surgical interventions for treating humeral shaft fractures in adults. Cochrane Database Syst Rev. 2012; 1:CD008832.

23. Ekholm R, Adami J, Tidermark J, Hansson K, Törnkvist $\mathrm{H}$, Ponzer S. Fractures of the shaft of the humerus. An epidemiological study of 401 fractures. J Bone Joint Surg. 2006; 88-B:1469-73.

24. Garnavos C. Intramedullary nailing for humeral shaft fractures: the misunderstood poor relative. Curr Orthop. 2001; 15:68-75.

25. Dabezies EJ, Banta CJ, Murphy CP et al. Plate fixation of the humeral shaft for acute fractures, with and without radial nerve injuries. J Orthop Trauma. 1992; 6:10-13.

26. Heim D, Herkert F, Hess P et al. Surgical treatment of humeral shaft fractures-the basel experience. The journal of trauma: Injury Infection and critical care. 1993; $35: 226-32$. 